\title{
Tropospheric profiles of wet refractivity and humidity from the combination of remote sensing data sets and measurements on the ground
}

\author{
F. Hurter ${ }^{1}$ and O. Maier ${ }^{2}$ \\ ${ }^{1}$ Geodesy and Geodynamics Laboratory, Institute of Geodesy and Photogrammetry, ETH Zurich, Switzerland \\ ${ }^{2}$ Federal Office of Meteorology and Climatology MeteoSwiss, Station aérologique, 1530 Payerne, Switzerland \\ Correspondence to: F. Hurter (fhurter@phys.ethz.ch)
}

Received: 31 March 2013 - Published in Atmos. Meas. Tech. Discuss.: 3 June 2013

Revised: 27 September 2013 - Accepted: 7 October 2013 - Published: 14 November 2013

\begin{abstract}
We reconstruct atmospheric wet refractivity profiles for the western part of Switzerland with a least-squares collocation approach from data sets of (a) zenith path delays that are a byproduct of the GPS (global positioning system) processing, (b) ground meteorological measurements, (c) wet refractivity profiles from radio occultations whose tangent points lie within the study area, and (d) radiosonde measurements. Wet refractivity is a parameter partly describing the propagation of electromagnetic waves and depends on the atmospheric parameters temperature and water vapour pressure. In addition, we have measurements of a lower Vband microwave radiometer at Payerne. It delivers temperature profiles at high temporal resolution, especially in the range from ground to $3000 \mathrm{~m}$ a.g.l., though vertical information content decreases with height. The temperature profiles together with the collocated wet refractivity profiles provide near-continuous dew point temperature or relative humidity profiles at Payerne for the study period from 2009 to 2011.

In the validation of the humidity profiles, we adopt a twostep procedure. We first investigate the reconstruction quality of the wet refractivity profiles at the location of Payerne by comparing them to wet refractivity profiles computed from radiosonde profiles available for that location. We also assess the individual contributions of the data sets to the reconstruction quality and demonstrate a clear benefit from the data combination. Secondly, the accuracy of the conversion from wet refractivity to dew point temperature and relative humidity profiles with the radiometer temperature profiles is examined, comparing them also to radiosonde profiles.
\end{abstract}

For the least-squares collocation solution combining GPS and ground meteorological measurements, we achieve the following error figures with respect to the radiosonde reference: maximum median offset of relative refractivity error is $-16 \%$ and quartiles are $5 \%$ to $40 \%$ for the lower troposphere. We further added 189 radio occultations that met our requirements. They mostly improved the accuracy in the upper troposphere. Maximum median offsets have decreased from $120 \%$ relative error to $44 \%$ at $8 \mathrm{~km}$ height. Dew point temperature profiles after the conversion with radiometer temperatures compare to radiosonde profiles as to: absolute dew point temperature errors in the lower troposphere have a maximum median offset of $-2 \mathrm{~K}$ and maximum quartiles of $4.5 \mathrm{~K}$. For relative humidity, we get a maximum mean offset of $7.3 \%$, with standard deviations of 12 $20 \%$.

The methodology presented allows us to reconstruct humidity profiles at any location where temperature profiles, but no atmospheric humidity measurements other than from GPS are available. Additional data sets of wet refractivity are shown to be easily integrated into the framework and strongly aid the reconstruction. Since the used data sets are all operational and available in near-realtime, we envisage the methodology of this paper to be a tool for nowcasting of clouds and rain and to understand processes in the boundary layer and at its top. 


\section{Introduction}

Up to this date, several techniques have been developed to remotely monitor the atmospheric water vapour, being a key variable in numerical weather prediction models. Among these are e.g. microwave radiometry, infrared spectrometry, radio occultation, differential absorption lidar and Raman Lidar remote sensing. Furthermore, processing of GNSS (global navigation satellite system) data delivers an integral measure of water vapour content at temporal resolution of at least $30 \mathrm{~min}$ (Bender et al., 2011a). This measure is defined by the delay of the electromagnetic wave that travels from the satellite through the atmosphere to the GNSS receiver. It includes the total influence of the atmosphere along its path, also that of the water vapour. With sophisticated software packages, the delay can be retrieved at each GNSS station. To obtain a profile of atmospheric water vapour from the delays, a GNSS receiver network, ground meteorological stations and profiles of atmospheric air temperature are needed. There are many studies that have used a tomographic approach to reconstruct humidity fields from GNSS delays. They either process path delays from stations of permanent GNSS networks (Perler et al., 2011), or from campaign setups, as in the ESCOMPTE experiment in France (Champollion et al., 2005; Nilsson et al., 2007; Bastin et al., 2007). Further works that exploit the tomographic approach are Nilsson and Gradinarsky (2006), Bender et al. (2009, 2011b), Rohm and Bosy (2011), Bosy et al. (2012), Manning et al. (2012) and Rohm (2013).

In this paper, the GPS (global positioning system) zenith delays from permanent GNSS stations are taken as the basis to monitor the atmospheric water vapour above Payerne, Switzerland, the MeteoSwiss launch site of operational radiosondes. Our choice for GPS path delays as the primary data set was motivated by its good time resolution, its allweather capability, the stable and high data availability, low maintenance and the fact that financing can be shared with other applications (e.g. GNSS reference networks for positioning). The integral measures of several GPS receivers are interpolated to profiles of so-called wet refractivity $\left(N_{\text {wet }}\right)$, which depends on both atmospheric temperature and water vapour pressure. For the interpolation, we employ an algorithm termed least-squares collocation. It incorporates a deterministic trend function and fits this function together with statistical parameters to the data that can be of many different types. Herein, we make use of the integral measures from GPS and of point measurements from ground meteorological stations and radio occultations. To demonstrate the effects caused by the collocation algorithm, we also conduct tests including the radiosonde data set, which is otherwise used for validation of the method's performance. Temperature profiles from a lower V-band $(51-58 \mathrm{GHz})$ microwave radiometer (Löhnert and Maier, 2012) in Payerne allow the conversion of wet refractivity profiles into vertical profiles of dew point temperature and relative humidity at the radiometer location.
This conversion can be carried out at any location where temperature profiles are available. Temperature radiometers like TEMPRO or other less expensive radiometers or automated weather reports from commercial airplanes could be the sources of such temperature profiles. In the validation of the profiles, more emphasis has been placed on the wet refractivity than on the humidity profiles. This procedure has been chosen on purpose because we want to thoroughly characterize the uncertainties associated with GPS atmospheric measurements before mingling with the uncertainties from temperature measurements.

In Sect. 2, we describe the used data sets. Section 3 explains the least-squares collocation algorithm from which we derive profiles of wet refractivity and explains how the data sets of integral and point measurements can be combined into a common collocation. We then demonstrate in Sect. 4 the performance of the algorithm with $3 \mathrm{yr}$ of data that is validated against the radiosonde, whose launch site is in Payerne. We also show the beneficial effect of the data set combination. Eventually, Sect. 5 sets the findings into the context of tomography results from other researchers and compares them to a study of humidity profile measurements from a Raman Lidar stationed in Payerne (Brocard et al., 2013) and to results from numerical weather prediction.

\section{Description of data sets}

This study makes use of data from January 2009 to December 2011 (Table 1) at the MeteoSwiss Regional Center of Payerne and locations within $\approx 100 \mathrm{~km}$ distance. The GPS data, being the main source of information for the spatial distribution of humidity in our study, and further data sets such as ground meteorological data, radio-soundings, radio occultations and vertical temperature profiles from the ground-based microwave radiometer that complete the retrieval of humidity from wet refractivity, are detailed in the following.

\subsection{GPS zenith path delays}

GNSS satellites transmit electromagnetic waves in the Lband, which travel from the satellite's orbit position to the receiver on the earth's ground. On its way across the atmosphere, the waves get bent and slowed down, causing a delay in the arrival at the receiver. The parameter called refractivity describes the propagation of radio waves and can be well determined for the neutral part of the atmosphere from basic thermodynamic parameters at any point in space and time where measurements of these parameters are available (Essen and Froome, 1951):

$N_{\mathrm{tot}}=N_{\mathrm{dry}}+N_{\mathrm{wet}}=k_{1} \cdot \frac{p_{\mathrm{d}}}{T}+k_{2} \cdot \frac{e}{T}+k_{3} \cdot \frac{e}{T^{2}}$,

with the two contributions to total refractivity $N_{\text {tot }}$ being 
Table 1. Overview of data sets used in this study.

\begin{tabular}{|c|c|c|c|c|c|}
\hline Sensor name & Start of data set [UTC] & End of data set [UTC] & Time resolution & $\begin{array}{l}\text { Number of } \\
\text { stations }\end{array}$ & Data provider \\
\hline radiosonde & 1 Jan 2009 00:00:00 & 31 Dec 2011 00:00:00 & $\begin{array}{l}2 \text { profiles/day at 00:00:00 } \\
\text { and 12:00:00 UTC }\end{array}$ & 1 & meteoswiss \\
\hline GPS & 28 Dec 2008 00:00:00 & 30 Dec 2011 23:00:00 & $1 \mathrm{~h}$ & 18 & swisstopo \\
\hline ground meteo & 1 Jan 2009 00:00:00 & 31 Dec 2011 00:00:00 & $10 \min$ & 20 & meteoswiss \\
\hline microwave radiom. & 1 Jan 2009 00:00:00 & 31 Dec 2011 23:53:20 & 6 to $7 \mathrm{~min}$ & 1 & meteoswiss \\
\hline radio occult. & 1 Jan 2009 & 21 Dec 2011 & 189 profiles & - & CDAAC \\
\hline
\end{tabular}

$N_{\text {dry }}=k_{1} \cdot \frac{p_{\mathrm{d}}}{T}$

$N_{\mathrm{wet}}=k_{2} \cdot \frac{e}{T}+k_{3} \cdot \frac{e}{T^{2}}$

$k_{1}=77.6890 \mathrm{~K} \mathrm{hPa}^{-1}$

$k_{2}=71.2952 \mathrm{~K} \mathrm{hPa}^{-1}$

$k_{3}=375463 \mathrm{~K}^{2} \mathrm{hPa}^{-1}$

$p_{\mathrm{d}}:$ dry air pressure $[\mathrm{hPa}]$

$e:$ water vapour pressure $[\mathrm{hPa}]$

$T:$ air temperature $[\mathrm{K}]$,

where $k_{1}, k_{2}$, and $k_{3}$ are empirically determined constants that have been reported by many researchers. For our investigations, we use the values estimated by Rüeger (2002). Since $p_{\mathrm{d}}, e$, and $T$ are functions of space and time, also $N_{\text {tot }}$ depends on position and time. For reasons of simplicity, we will always assume $N_{\text {tot }}=N_{\text {tot }}(x, y, z, t)$. Refractivities are in units of ppm or $\mathrm{mm} \mathrm{km}^{-1}$, which expresses the delay caused by the neutral atmosphere per kilometer of propagation path. The integral of the refractivity $N_{\text {tot }}$ along the propagation path $s$ from satellite $q$ to receiver $r$ yields the total propagation delay $\Delta^{\mathrm{PD}}$.

$\Delta^{\mathrm{PD}}=10^{-6} \int_{q}^{r} N_{\text {tot }} \mathrm{d} s$

There is such a delay for each satellite-receiver pair. If they were to be estimated individually by a piece of GNSS processing software, the number of unknown parameters would be too large and their correlation to other parameters too strong to be properly handled. Mapping functions are introduced that project all delays for a station onto a common zenith direction. The mapped delays are then averaged producing one atmospheric parameter at a time, the so-called total zenith path delay (ZTD). Traditionally, the total zenith path delay is split into a slowly varying dry (ZDD) and a more variable wet (ZWD) part, corresponding to the integrals of $N_{\text {dry }}$ and $N_{\text {wet }}$, respectively. The path integral of the refractivities in zenith direction then becomes the total zenith delay:

$$
\begin{aligned}
\mathrm{ZTD}= & \mathrm{ZDD}+\mathrm{ZWD} \\
& \approx 10^{-6} \int_{\begin{array}{c}
\text { zenith } \\
\text { direction }
\end{array}}\left(N_{\text {dry,average }}+N_{\text {wet,average }}\right) \mathrm{d} s,
\end{aligned}
$$

where $N_{\text {dry,average }}$ and $N_{\text {wet, average }}$ represent horizontal averages in a cone around the receiving antenna and temporal averages over the epochs used in the GNSS processing. Apart from 1 May 2011 00:00:00 UTC to 4 June 2011 23:50:00 UTC where some problems in storing the data occurred (E. Brockmann, personal communication, 2012), $3 \mathrm{yr}$ of hourly ZTDs were provided by swisstopo, the Swiss Federal Office of Topography (Table 1). Figure 1 shows the considered GNSS receivers, which belong to the Automated GNSS Network for Switzerland (AGNES). They are distributed over an area of $125 \mathrm{~km} \times 125 \mathrm{~km}$ around Payerne and have inter-station distances between a few kilometers and $50 \mathrm{~km}$. Some stations also recorded data from the Russian global navigation satellite system GLONASS, but only the US global positioning system (GPS) was used to derive the zenith total path delays for this study. In the following, we will thus use GPS synonymously to GNSS. The processing carried out by swisstopo is based on the same procedure as described in Perler et al. (2011), or in more detail in Perler (2011), and uses the Bernese GNSS Software Version 5.0 (Dach et al., 2007). Mapping functions applied are dry Niell for the a priori part of the troposphere and wet Niell for the estimated part (Niell, 1996). Together, they form the total zenith path delays that are determined by the software once per hour. In between, the temporal change of the troposphere is modeled with a piecewise linear function. The rapid orbits from the International GNSS Service (IGS) have been used in the processing, allowing near real-time applications of the GPS path delays. They have been shown to have accuracies good enough for meteorological applications (Lutz, 2009).

\subsection{Meteorological ground stations}

From the permanent and automatic ground meteorological measurement network called SwissMetNet of the Swiss Federal Office of Meteorology and Climatology (MeteoSwiss), 14 to 19 stations within the perimeter of study were concurrently measuring pressure, temperature and relative humidity 


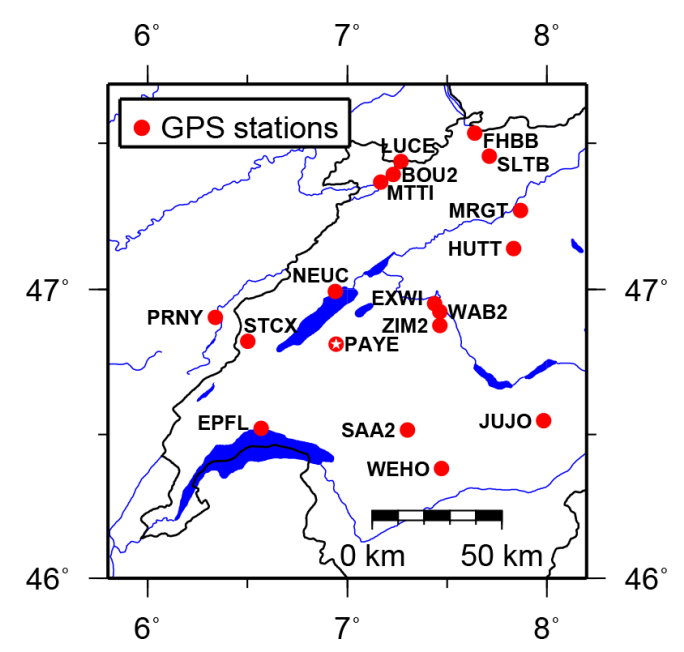

Fig. 1. GPS stations whose zenith path delays contribute to this study. They are all stations from the AGNES, deployed by the Swiss Federal Office of Topography. White star in Payerne denotes the place of the profile comparison.

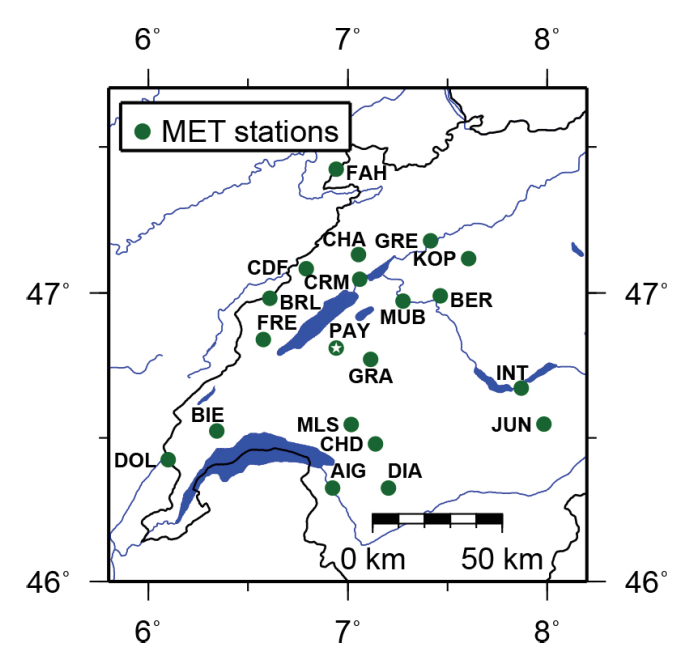

Fig. 2. SwissMetNet (SMN) stations of MeteoSwiss used in this study.

during the $3 \mathrm{yr}$ of our investigation (Table 1). Figure 2 displays the considered ground meteo stations and Fig. 3 the height distribution of these stations, together with the GPS stations. Uncertainties given in Table 2 are from general working experience with these sensors and correspond to their achievable measurement uncertainties that have been listed in CIMO Guide (2008).

\subsection{Radiosonde profiles in Payerne}

The radiosonde data comprises profiles from $3 \mathrm{yr}$ of continuous operation (Table 1) at the MeteoSwiss Regional Center of Payerne. Most days contain 2 launches at midnight and at noon (exceptional days include a third sounding around 18:00 UTC). At 00:00 UTC and 12:00 UTC, the

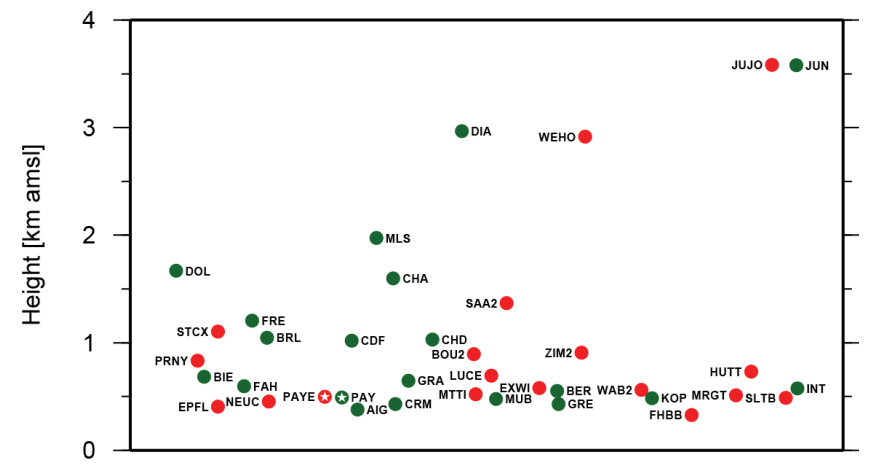

Fig. 3. Height distribution of the GPS (red) and ground meteorological stations (green) shown in Figs. 1 and 2, projected into a westeast plane. Their longitudinal positions were shifted to improve label readability.

sondes should approximately reach $20 \mathrm{~km}$ height, which is why they are launched 1 hour in advance. Depending on the tropopause height, they reach the tropopause $30-45 \mathrm{~min}$ after launch. The parameters that are important for this study and are contained in the original data are shown in Table 2. Also shown in Table 2 are respective sensor uncertainties as given by Löhnert and Maier (2012). They comply with the working experience at MeteoSwiss and with the experience gained from intercomparison with other radiosonde systems (Nash et al., 2011).

\subsection{Radio occultations}

From the COSMIC Data Analysis and Archive Center (CDAAC, Version 4.0), post-processed data products of radio occultations (radio occult. in Tables 1 and 2) taking place during the period 2009-2011 and with tangent points lying in the investigation area (Fig. 1) were downloaded. They consist mostly of data from the COSMIC mission, but also occultations from the GRACE, the MetOp-A, the SACC and the TerraSar-X missions are included. Processing flow of these data is outlined in Ho et al. (2009) and Kuo et al. (2004). From the data product wetPrf, containing water vapour pressure and temperature profile data from a variational analysis of total refractivity (described in VARS Documentation, 2005), profiles of wet refractivity (Eq. 3) were calculated up to a maximum height of $11 \mathrm{~km}$. For uncertainty measures, the uncertainties from the product atmPrf were taken. Approximate values are given in Table 2. For the middle to upper troposphere they are consistent with the values given in Kuo et al. (2004) of roughly $0.3-0.5 \%$ or in Scherllin-Pirscher et al. (2011) of roughly $0.5 \%$ relative total refractivity uncertainty. For the lower troposphere they give tentative relative uncertainties of $\approx 5 \%$, which do not match the values in atmPrf, being most likely too optimistic. For the region in the lower troposphere, where the formal uncertainties failed to be calculated, a default value of $1 \mathrm{ppm}$ was adopted but needs further refinement in the future. However, 
Table 2. Parameters contained in the original data sets and associated sensor uncertainties.

\begin{tabular}{|c|c|c|c|}
\hline Sensor name & Parameter & Uncertainty & Remark \\
\hline radiosonde $^{\mathrm{a}}$ & $\begin{array}{l}\text { temperature } \\
\text { pressure } \\
\text { humidity }\end{array}$ & $\begin{array}{l} \pm 0.2 \mathrm{~K} \\
\pm 0.2 \% \text { of value } \cong \pm 2 \mathrm{hPa} \\
\pm 10 \text { to } 20 \% \\
\pm 5 \text { to } 10 \%\end{array}$ & $\begin{array}{l}\text { copper-constantan } \\
\text { thermocouples, } \\
\text { water hypsometer, } \\
\text { carbon hygristor } \\
\text { until April } 2009 \text {, } \\
\text { capacitive polymer } \\
\text { starting May } 2009\end{array}$ \\
\hline GPS & total zenith path delay & $1.6 \mathrm{~mm}$ & $\begin{array}{l}\text { average formal uncertainty } \\
\text { from GPS processing of } \\
\text { L1/L2 dual-frequency } \\
\text { geodetic GNSS receivers }\end{array}$ \\
\hline \multirow[t]{3}{*}{ ground meteo ${ }^{b}$} & temperature & $\pm 0.2 \mathrm{~K}$ & $\begin{array}{l}\text { achievable measurement } \\
\text { uncertainty, }\end{array}$ \\
\hline & pressure & $\pm 0.15 \mathrm{hPa}$ & $\begin{array}{l}\text { achievable measurement } \\
\text { uncertainty, }\end{array}$ \\
\hline & relative humidity & $\pm 3 \%$ & $\begin{array}{l}\text { achievable measurement } \\
\text { uncertainty }\end{array}$ \\
\hline microwave radiom. ${ }^{\mathrm{c}}$ & temperature & $\begin{array}{l} \pm 0.5 \mathrm{~K} \text { lower boundary layer } \\
\pm 1.7 \mathrm{~K} \text { at } 4 \mathrm{~km} \text { height }\end{array}$ & $\begin{array}{l}\text { standard deviations } \\
\text { from comparison with } \\
\text { radiosondes }\end{array}$ \\
\hline radio occult. & total refractivity & $\begin{array}{l}\approx \pm 1 \mathrm{ppm} \text { at } 1.0 \mathrm{~km} \text { height } \\
\pm 2 \mathrm{ppm} \text { at } 4 \mathrm{~km} \text { height } \\
\pm 0.03 \mathrm{ppm} \text { at } 8 \mathrm{~km} \text { height }\end{array}$ & $\begin{array}{l}\text { average formal } \\
\text { uncertainties from } \\
\text { operational level } 2 \text { product }\end{array}$ \\
\hline
\end{tabular}

${ }^{\mathrm{a}}$ Löhnert and Maier (2012), ${ }^{\mathrm{b}}$ CIMO Guide (2008), ${ }^{\mathrm{c}}$ Löhnert and Maier (2012)).

all these uncertainties refer to total refractivity, being the sum of dry and wet refractivity according to Eq. (1), and hence are only approximate measures of wet refractivity uncertainty. They are considered to be conservative for at least the middle and the upper troposphere, where the variational analysis successfully extracts temperature and dry pressure (Scherllin-Pirscher et al., 2011), but probably too optimistic for the lower troposphere. Positions of the occultation profiles have been taken along the longitude and latitude of the tangent points from the operational processing, being a good approximation of the true tangent point trajectories from raytracing (Foelsche et al., 2011).

\subsection{Ground-based microwave radiometer for temperature profiling}

Profiles of temperature at Payerne from ground-based microwave radiometry (microwave radiom. in Table 1) have been provided by the CN-MET (Centrale Nucléaire et Météorologie) network of MeteoSwiss. A longer period of maintenance from 8 May 2009 07:10:00 UTC to 17 September 2009 12:50:00 UTC (Löhnert and Maier, 2012) and some smaller periods of missing data are the only data gaps in an otherwise continuous $3 \mathrm{yr}$ data set. The deployed device is the microwave profiler system HATPRO (Humidity
And Temperature PROfiler), whose original data output are brightness temperatures in the V-band with seven channels ranging from 51 to $58 \mathrm{GHz}$. A detailed description of the system can be found in Löhnert and Maier (2012). All-weather data is used, including precipitation events. Bias removal was kept very simple by retrieving one mean temperature difference to radiosonde at each height level for the entire study period 2009-2011 and applying these differences to individual radiometer profiles.

The reader might be inclined to ask why we use wet refractivity from GPS as humidity information and not the humidity sensor from the radiometer. The answer lies in the aim of the study: to derive humidity profiles at locations where only temperature profiles are available. The fact that the radiometer in Payerne is a HATPRO is not relevant for this study.

\section{Retrieval of wet refractivity and humidity profiles}

There are a number of applications, for which we need to know the atmospheric state at various locations that do not coincide with actual measurement locations. To interpolate and extrapolate such quantities from real meteorological measurement stations to arbitrary locations, the software package COMEDIE was developed at the Geodesy and 


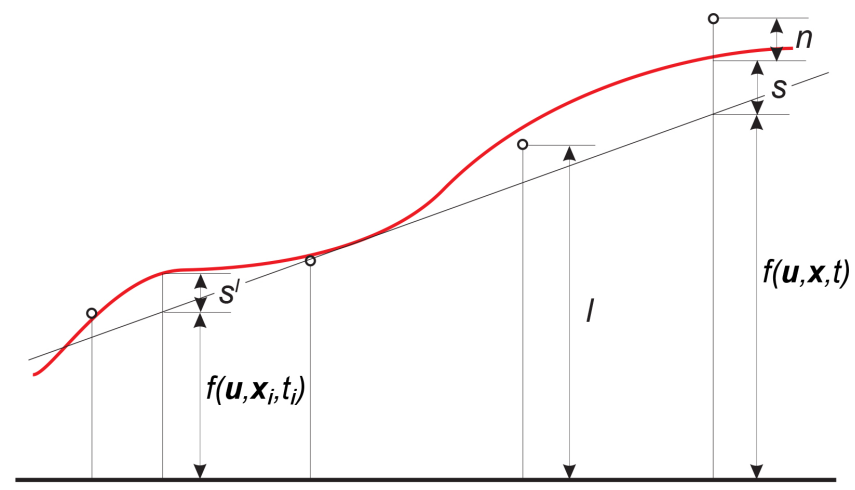

Fig. 4. Principle of collocation (Troller, 2004). The circles are the measurements $l$, which are comprised of a deterministic part $f(\boldsymbol{u}, \boldsymbol{x}, t)$, of signal $s$ and noise $n$. Interpolation between measurements then is a filtered version that is made up of the deterministic part $f\left(\boldsymbol{u}, \boldsymbol{x}_{i}, t_{i}\right)$ at the interpolated position $\boldsymbol{x}_{i}$ and time $t_{i}$, plus the signal $s^{\prime}$.

Geodynamics Lab at ETH Zürich, Switzerland (e.g. Eckert et al., 1992a, b; Hirter, 1998; Troller, 2004). COMEDIE is equipped with a least-squares collocation algorithm that has its main geophysical application in the estimation of gravity anomalies from various types of measurements, such as the gravitational potential, the gravitational force or the deflection of the vertical (Moritz, 1978). Several processing steps in this study rely on COMEDIE. Above all, the reconstruction of wet refractivity profiles at Payerne from ZWDs and, in a more advanced version of the algorithm, from the combination of ZWDs with $N_{\text {wet }}$ from point measurements, are carried out with COMEDIE. A short theoretical description of the least-squares collocation is given in this section.

\subsection{Least-squares collocation algorithm}

We have measurements $l$ (Fig. 4) that are adjusted in the least-square sense to a deterministic part $f(\boldsymbol{u}, \boldsymbol{x}, t)$, and to stochastic parts $s$ and $n$ (modified after Troller, 2004):

$l=f(\boldsymbol{u}, \boldsymbol{x}, t)+s+n$,

where:

$l$ :

$f(\boldsymbol{u}, \boldsymbol{x}, t)$ : function describing general field of

measured values

$\boldsymbol{u}: \quad$ unknown parameters

$\boldsymbol{x}, t: \quad$ coordinates in space and time

$s: \quad$ stochastic parameter $s \sim \mathcal{N}\left(0 ; \mathbf{C}_{s s}\right)$

$n: \quad$ stochastic parameter $n \sim \mathcal{N}\left(0 ; \mathbf{C}_{n n}\right)$

The deterministic part is a function that describes the general shape of the measurements (Fig. 4). We employ the following deterministic functions for dry air pressure $p$, water vapour pressure $e$ and ZWD:

$$
\begin{aligned}
& p(x, y, z, t)= \\
& {\left[p_{0}+a_{p}\left(x-x_{0}\right)+b_{p}\left(y-y_{0}\right)+c_{p}\left(t-t_{0}\right)\right] \cdot \exp \left(-\frac{z}{H_{p}}\right)} \\
& e(x, y, z, t)= \\
& {\left[e_{0}+a_{e}\left(x-x_{0}\right)+b_{e}\left(y-y_{0}\right)+c_{e}\left(t-t_{0}\right)\right] \cdot \exp \left(-\frac{z}{H_{e}}\right)} \\
& \mathrm{ZWD}(x, y, z, t)= \\
& {\left[\mathrm{ZWD}_{0}+a_{\mathrm{ZWD}}\left(x-x_{0}\right)+b_{\mathrm{ZWD}}\left(y-y_{0}\right)+c_{\mathrm{ZWD}}\left(t-t_{0}\right)\right] \cdot \exp \left(-\frac{z}{H_{\mathrm{ZWD}}}\right)}
\end{aligned}
$$

$x_{0}, y_{0}, t_{0}:$

$$
\text { coordinates of reference point and }
$$
reference time

$x, y, z, t:$ Cartesian coordinates and time

$p_{0}, e_{0}, \mathrm{ZWD}_{0}$ : pressure, water vapour pressure and ZWD at reference position and time

$H, a, b, c:$ scale height, and gradient parameters in $x$ and $y$ direction and time, respectively. Subscripts denote their affiliation to $p, e$ and ZWD.

The covariance matrix $\mathbf{C}_{s s}$ of the stochastic parameter $s$ is described with an analytical covariance function showing spatial and temporal dependencies between measurements. In the literature, it is also termed the signal part of the measurements. The henceforth used covariance function is a function of the distance between the measurements, how much they differ in time, and a scaling factor that increases the correlation lengths with height aboveground (Hirter, 1998).

$\mathbf{C}_{s s}\left(\mathrm{ZWD}_{k}, \mathrm{ZWD}_{l}\right)=\frac{\sigma_{\text {signal }}^{2}}{q}$,

where we have for $q$ :

$$
\begin{aligned}
q & =1+\left[\left(\frac{x_{k}-x_{l}}{\Delta x_{0}}\right)^{2}+\left(\frac{y_{k}-y_{l}}{\Delta y_{0}}\right)^{2}+\left(\frac{z_{k}-z_{l}}{\Delta z_{0}}\right)^{2}\right. \\
& \left.+\left(\frac{t_{k}-t_{l}}{\Delta t_{0}}\right)^{2}\right] \cdot \exp \left(-\frac{z_{k}+z_{l}}{2 z_{0}}\right)
\end{aligned}
$$

$\sigma_{\text {signal }}^{2}:$

$x_{k}, y_{k}, z_{k}, t_{k}$ :

$x_{l}, y_{l}, z_{l}, t_{l}:$

$z_{0}:$ a priori covariance of signal

Cartesian coordinates and time of observation $k$ Cartesian coordinates and time of observation $l$ scale length modifying correlation lengths as a function of height

$\Delta x_{0}, \Delta y_{0}, \Delta z_{0}, \Delta t_{0}: \quad$ correlation lengths of space and time 
Table 3. List of stochastic parameters applied in the least-squares collocation. For signal part $s$, see Eq. (10).

\begin{tabular}{llllllll}
\hline Observation & $\sigma_{\text {signal }}$ & $\sigma_{\text {noise }}$ & $\Delta x_{0}$ & $\Delta y_{0}$ & $\Delta z_{0}$ & $\Delta t_{0}$ & $z_{0}$ \\
\hline Pressure & $6 \mathrm{hPa}$ & $0.5 \mathrm{hPa}$ & $200 \mathrm{~km}$ & $150 \mathrm{~km}$ & $0.50 \mathrm{~km}$ & $3.8 \mathrm{~h}$ & $4 \mathrm{~km}$ \\
Water vapor pressure & $2 \mathrm{hPa}$ & $0.5 \mathrm{hPa}$ & $75 \mathrm{~km}$ & $50 \mathrm{~km}$ & $0.15 \mathrm{~km}$ & $1.7 \mathrm{~h}$ & $4 \mathrm{~km}$ \\
ZWD & $1.2-5 \mathrm{~mm}$ & $2 \mathrm{~mm}$ & $35 \mathrm{~km}$ & $35 \mathrm{~km}$ & $1 \mathrm{~km}$ & $4 \mathrm{~h}$ & $4 \mathrm{~km}$ \\
\hline
\end{tabular}

The stochastic parameter $n$ is described with the covariance matrix $\mathbf{C}_{n n}$ containing the noise of the individual measurements in the diagonal elements and with all off-diagonal elements being zero. This noise has been calculated with the uncertainties given in Table 2.

The collocation eventually estimates in a least-squares sense the parameters of the deterministic function $(a, b, c$, $H$ and $p_{0}, e_{0}$ and $\mathrm{ZWD}_{0}$ for the respective fields) and the signal and noise part of each measurement. The collocation also allows the interpolation of these parts to the points where no measurements are available (see Fig. 4).

\subsection{Combined collocation of ZWDs and wet refractivities}

For the combined collocation, we need to describe the relationship between the two measurements. Since $N_{\text {wet }}$ is the derivative of the ZWD in zenith direction (Eq. 5), the two observation equations become

$l_{\mathrm{ZWD}}=f(\boldsymbol{u}, \boldsymbol{x}, t)+s+n$

$l_{N \text { wet }}=D(f(\boldsymbol{u}, \boldsymbol{x}, t)+s+n)$

with

$l_{\text {ZWD }}: \quad$ ZWD measurement

$l_{N \text { wet }}$ : $\quad N_{\text {wet }}$ measurement

$f(\boldsymbol{u}, \boldsymbol{x}, t)$ : function describing general ZWD field

$\boldsymbol{u}$ : unknown parameters of ZWD field

$\boldsymbol{x}, t: \quad$ coordinates in space and time

$s: \quad$ signal part with respect to ZWD

$n$ : $\quad$ noise part with respect to ZWD

$D$ : $\quad$ differential operator relating ZWD to refractivity $N_{\text {wet }}$

and where $D$ :

$D=-\frac{\partial}{\partial z}$.

As the differential operator is applied to the deterministic part of the ZWD (Eq. 10), we obtain

$N_{\text {wet }}(x, y, z, t)=D Z W D(x, y, z, t)$

$=\frac{1}{H}\left[\mathrm{ZWD}_{0}+a\left(x-x_{0}\right)+b\left(y-y_{0}\right)+c\left(t-t_{0}\right)\right] \cdot \exp \left(-\frac{z}{H}\right)$.

Applying the differential operator to the signal of the stochastic part leads to two different covariance matrices. In the first case, the covariance between ZWD and $N_{\text {wet }}$ is derived. In a second case, we seek the covariance between two refractivities $N_{\text {wet, } k}$ and $N_{\text {wet }, l}$. In case 1 :

$\mathbf{C}_{s s}\left(N_{\text {wet }}, \mathrm{ZWD}\right)=\mathbf{C}_{s s}\left(\mathrm{ZWD}, N_{\text {wet }}\right)$

$=\frac{\sigma_{\text {signal }}^{2}}{q^{2}}\left[\frac{2 \cdot\left(-z_{\mathrm{ZWD}}+z_{N \text { wet }}\right)}{\left(\Delta z_{0}\right)^{2}} \cdot \exp \left(-\frac{z_{N \text { wet }}+z_{\mathrm{ZWD}}}{2 z_{0}}\right)+\frac{1-q}{2 z_{0}}\right]$.

In case 2:

$\mathbf{C}_{s s}\left(N_{\text {wet }, k}, N_{\text {wet }, l}\right)=\mathbf{C}_{s s}\left(N_{\text {wet }, k}, N_{\text {wet }, l}\right)$

$=\frac{2 \sigma_{\text {signal }}^{2}}{q^{2}}\left[\frac{\exp \left(-\frac{z_{k}+z_{l}}{2 z_{0}}\right)}{\left(\Delta z_{0}\right)^{2}}+\frac{(q-1)(q-2)}{8 q z_{0}^{2}}-\frac{4\left(z_{k}-z_{l}\right)^{2}}{q\left(\Delta z_{0}\right)^{4}} \cdot \exp \left(-\frac{z_{k}+z_{l}}{z_{0}}\right)\right]$.

The uncorrelated noise $n$ of the ZWD becomes the uncorrelated noise of the $N_{\text {wet }}$ measurements under the influence of the differential operator.

\subsection{Processing}

The flowchart in Fig. 5 gives an overview of the processing steps taken to obtain wet refractivity, dew point temperature and relative humidity profiles at Payerne. Rectangles with corresponding numbers denote processing steps explained in the following.

1. We obtain total air pressure and water vapour pressure estimates at the GPS stations from 20 ground meteorological stations with the individual collocation of the two parameters. We use the methodology and parameter setting outlined in Table 3 and Hirter (1998). Deterministic functions are given in Eq. (7) for pressure and Eq. (8) for water vapour pressure.

2. From the collocated air pressure and water vapour pressure values, zenith dry delays (ZDD) are calculated at the locations of the GPS stations (Lutz, 2009):

$\mathrm{ZDD}=0.002277 \cdot\left(p_{1}-0.155471 \cdot e_{1}\right)$,

where $p_{1}$ is the total air pressure $[\mathrm{hPa}]$ and $e_{1}$ the partial water vapour pressure $[\mathrm{hPa}]$ at the station, yielding ZDD in units of meters. Note that the water vapour pressure, whose collocation is inherently problematic due to its strong spatial and temporal variations, has only a minor influence onto the ZDD. This is why we can model the ZDD to millimeter accuracy from collocated ground meteo stations, as was demonstrated 


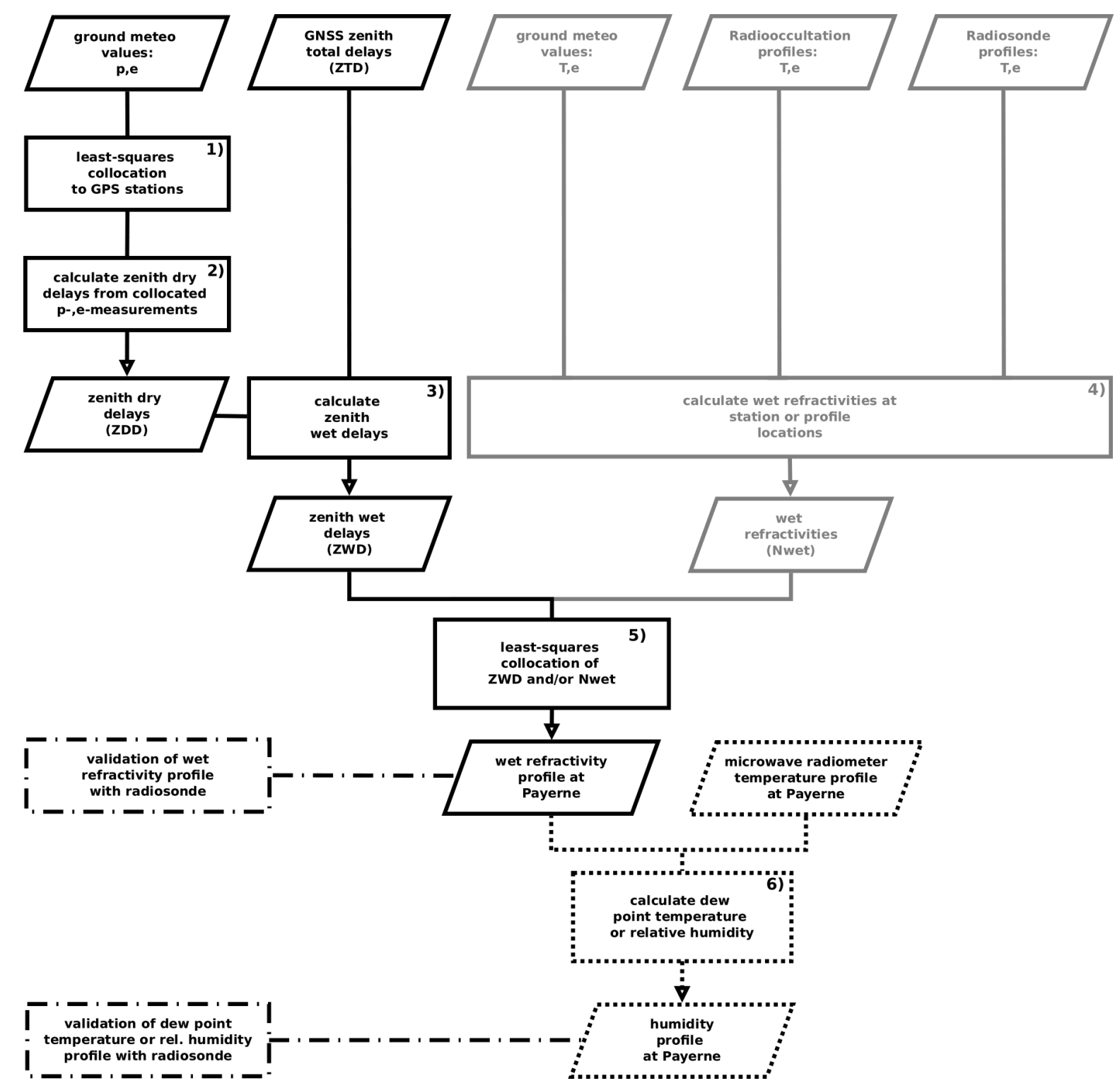

Fig. 5. Flowchart of the steps carried out to get wet refractivity or humidity profiles at Payerne. Rectangles stand for processing steps and parallelograms denote data and results from the processing. The numbers in the chart refer to the processing steps explained in Sect. 3.3. The solid lines show the processing that leads to the refractivity profiles. The second part of the study, where humidity profiles in Payerne are produced, is shown with dashed lines.

in Perler (2011). In a comparison between ZDD calculated from ground meteo (Eq. 17) and from radiosonde integration at Payerne, Perler (2011) obtains $1.6 \mathrm{~mm}$ standard deviation and a mean offset of $2.6 \mathrm{~mm}$ (ground meteo minus radiosonde).

3. The zenith total delays (ZTD) from the GPS processing are reduced to the zenith wet delays (ZWD) by subtracting easy-to-model dry zenith delays (ZDD) using results from the previous processing step:

$\mathrm{ZWD}=\mathrm{ZTD}-\mathrm{ZDD}$.
The uncertainty of the ZWD is very difficult to assess. It must be above the formal uncertainty given in Table 2 for the ZTD plus some uncertainty contribution added from the ZDD (see Eq. 18). We adopt a rather optimistic and tentative value of $2 \mathrm{~mm}$ (Table 3 ).

4. Wet refractivities are determined with Eq. (3) from several sources: ground meteo, radio occultation and radiosonde profiles. For ground meteo and radiosonde, uncertainties are calculated from error propagation of the values in Table 2, assuming no correlation between 
temperature and humidity readings. For radio occultations, see Sect. 2.4.

5. Different combinations of the ZWD and the $N_{\text {wet }}$ data sets have been input into a collocation using the methodology of Sect. 3.2. The settings for the covariance matrix of the stochastic parameter $s$ are listed in Table 3. Correlation lengths were set according to a rule of thumb that was derived from tests on synthetic data (not within the scope of this paper). Stable results were obtained, if correlation lengths were 4 times the average sampling in either space or time. Due to the large amount of data, collocations were carried out on batches of $8 \mathrm{~h}$ data with $1 \mathrm{~h}$ overlap to the next batch to ensure smooth continuation between the batches. Interpolated wet refractivities $N_{\text {wet }}$ are output at the heights in Payerne, where microwave radiometer derived air temperatures are also given.

6. $N_{\text {wet }}$ links the GPS data to meteorology. From the $N_{\text {wet }}$ and the radiometer temperature profiles, both at Payerne, we obtain profiles of water vapour pressure $e$ $[\mathrm{hPa}]$ rearranging Eq. (3). Dew point temperature $T_{\text {dew }}$ $[\mathrm{K}]$ is then calculated following Jacobson (2005):

$$
T_{\mathrm{dew}}=\frac{4880.357-29.66 \ln e}{19.48-\ln e} .
$$

For reasons of simple comparability with humidity profiles from other techniques, the profiles are also calculated in units of percent relative humidity according to

$$
f=\frac{e}{e_{\mathrm{sat}}} \cdot 100[\%]
$$

with

$$
e_{\text {sat }}=6.112 \cdot \exp \left(\frac{17.67 \cdot(T-273.15)}{(T-273.15)+243.5}\right) \text {, }
$$

where temperature $T$ is given in Kelvin and water vapour pressure $e$ and saturation vapour pressure $e_{\text {sat }}$ (Bolton, 1980) are both in units of [hPa].

\section{Results}

The results from the least-squares collocation algorithm are compared to radiosonde profiles in Payerne at two stages of the processing (see flowchart in Fig. 5). Firstly, we only investigate the profile quality of the wet refractivity profiles, which are the result of processing step 5 in Sect. 3.3. Secondly, profiles from processing step 6 in Sect. 3.3 are validated with radiosonde profiles of dew point temperature and relative humidity. Corresponding radiosonde profiles have been calculated using Eqs. (3), (19), and (20). Profiles that result from the COMEDIE processing will be called model.

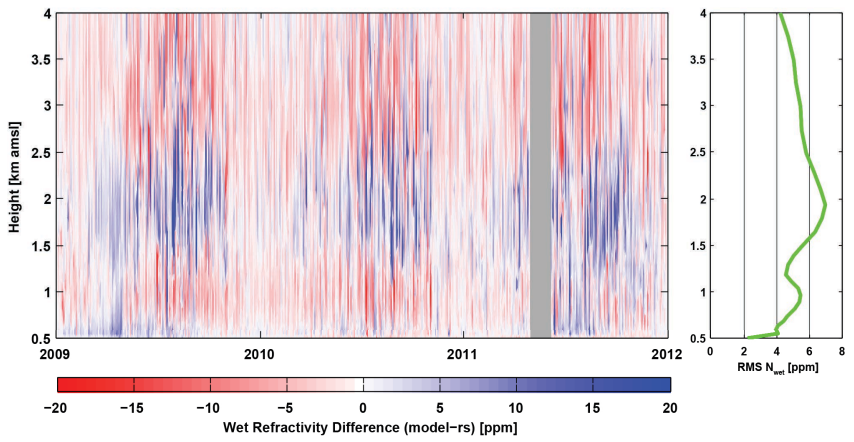

Fig. 6. Time series showing the difference between the COMEDIE derived wet refractivities from the GPS plus ground meteo data and the radiosonde (grey box: GPS data gap). The RMS difference for all $3 \mathrm{yr}$ is plotted on the side of the time series.

The radiosonde profiles are abbreviated as rs to simplify description of the results. Since the model can output a profile at any time, and we are mostly interested in the fast varying part of the lower troposphere, the comparison takes place at launch time of the radiosonde, that is, one hour before 00:00 UTC and 12:00 UTC.

\subsection{Wet refractivity profiles}

Figure 6 displays the time series of the difference between model and rs, where we combine the two data sets (GPS and ground meteo) in a common collocation. A clear seasonal trend is observed with strong positive values at heights around $2 \mathrm{~km}$ during the months June-October, coinciding with large negative values above and below. The systematic vertical deviation structure is caused by the algorithm that tries to achieve zero mean on the overall signal part (see Eq. 6) on the basis of the parameters in Table 3. This indicates that the algorithm's performance might be improved with a more sophisticated deterministic function and more appropriate stochastic parameters. We also mention here that the corresponding time series of relative differences (not shown) does not have a seasonal trend, meaning that differences are high when wet refractivity values are high and vice versa. The subfigure to the right gives the root mean square difference (RMS) for all $3 \mathrm{yr}$ and is a measure of interpolation quality. The RMS varies between 2 and $7 \mathrm{ppm}$ (corresponding to 5-80\% relative wet refractivity difference) below the maximum at $2 \mathrm{~km}$ and reaches $4 \mathrm{ppm}$ (130\% relative difference) at $4 \mathrm{~km}$ height.

Figure $7 \mathrm{a}$ and $\mathrm{b}$ shows two characteristic October profiles, comparing the COMEDIE solutions with the radiosonde. They are plotted with formal uncertainty bands and for 3 different input data sets. Input data sets include (i) ZWDs only, (ii) ZWDs and $N_{\text {wet }}$ from ground meteo and, (iii) ZWDs combined with $N_{\text {wet }}$ from ground meteo and from radiosonde derived wet refractivities. Uncertainty bands for the model solutions are calculated a posteriori during the least-squares 


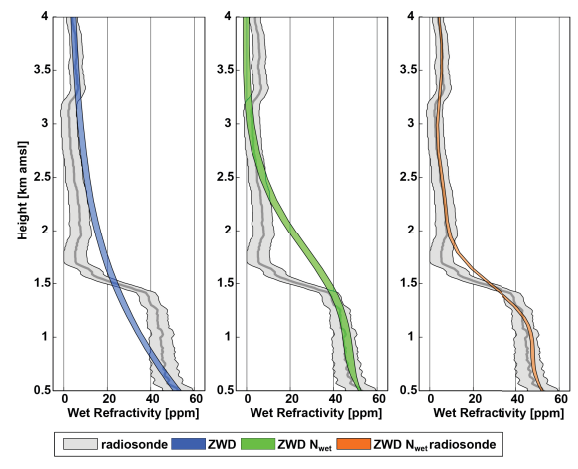

(a)

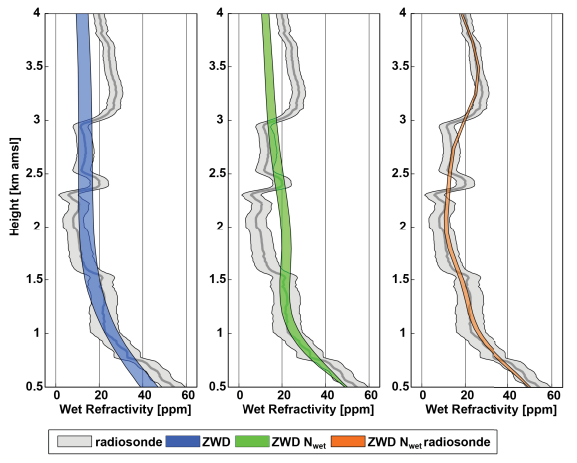

(b)

Fig. 7. Single profiles of wet refractivity for (a) 17 October 2011, 12:00 UTC and (b) 28 October 2011, 12:00 UTC for different input data sets. The formal 1-sigma uncertainty of the profiles and of the corresponding radiosonde are shown as shaded patches.

estimation. We note strong smoothing of the model profiles and underestimation of the actual error of the interpolation algorithm. This is not a surprise since the algorithm is not aware of all the variability that can occur in the atmosphere. Assumptions of these variabilities need to be made before the calculations and are input into Eq. (10). The coarser the network, the more difficult it becomes to derive those parameters from the data itself. Not having enough welldistributed data at hand in the 3 spatial dimensions and in time to derive all correlation lengths from the data alone, the rule of thumb mentioned in Sect. 3.3 has been employed, which is a simplistic approach to avoid undersampling of short wavelength structures, but needs to be reconsidered in future work. A more appropriate solution would probably be to derive the correlation lengths from numerical weather prediction model analysis. The rightmost plots of Fig. 7a and $b$ that contain the radiosonde in the collocation are not intended as validation but bear testimony to the smoothing effect caused by the parameter set of Table 3. The reconstructed profiles are not independent from the validation data set anymore, but demonstrate that collocation inherently acts as a kind of averaging kernel. The smoothing is partly responsible for the limited capability to reproduce strong vertical changes in the atmosphere that are frequent during summer and early autumn months. Additionally, the degrading effect from the inclusion of ground meteo around $2 \mathrm{~km}$ height, visible in the comparison between the ZWD only and the ZWD plus $N_{\text {wet }}$ solution, results to a large degree from ground meteo values that are not representative for the situation in Payerne. Responsible are the stations DOL, MLS and CHA (see Fig. 3) that generally show too high values compared to corresponding radiosonde values in Payerne.

On a single profile basis, Fig. 8a and b shows the difference of the model solution to the radiosonde rs at the same dates as in Fig. 7a and b, respectively. Colour coding and naming has been kept consistent with previous plots. In Fig. 8a and b, one previously unmentioned solution is shown in black. It represents the solution achieved, if only
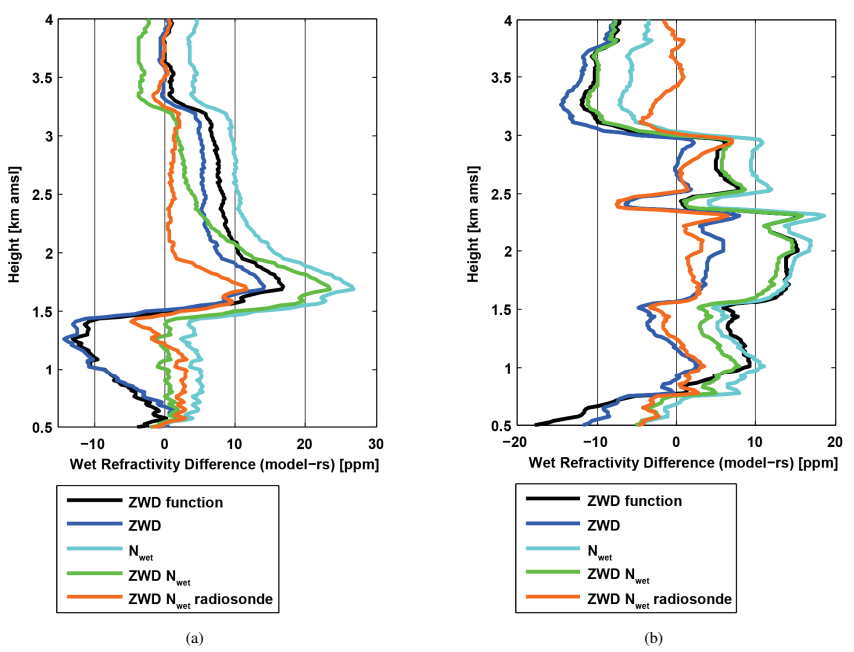

Fig. 8. (a) Comparison between interpolated refractivity profiles from COMEDIE and the radiosonde profile from the 17 October 2011, 12:00 UTC. ZWD function takes only the deterministic part into account. All other profiles also contain the signal part derived from either ZWD data from GPS, refractivity data from ground meteorological stations or the radiosonde at Payerne, or a combination of these data sets. (b) Comparison between interpolated refractivity profiles from COMEDIE and the radiosonde profile from the 28 October 2011, 12:00 UTC. Other information as for (a).

the deterministic part from the ZWD solution is compared to the radiosonde (see Sect. 3.1). The blue line shows how the solution benefits from the signal part. The improvement from the black to the blue line is especially obvious in Fig. 8b. The effect of the aforementioned stations DOL, MLS and CHA and of the smoothing of the applied correlation lengths are again well observed in all solutions shown.

A rough quantification of the loss in reconstruction quality in case of missing stations in a network is attempted in Fig. 9. It shows the RMS difference between the combined solution (GPS and ground meteo) and the radiosonde for the $3 \mathrm{yr}$ data. The light green curve includes all measurement stations and 


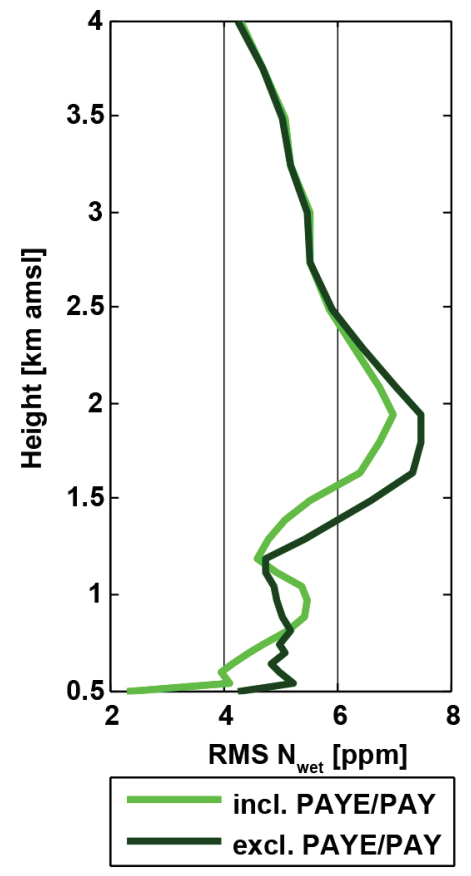

Fig. 9. RMS of model minus radiosonde difference for a collocation including the GPS station PAYE and the meteo station PAY (light green) and for a collocation without those two stations (dark green). The comparison shows $3 \mathrm{yr}$ of data with 2132 radiosonde profiles being evaluated. Note that the light green line corresponds to the right panel of Fig. 6, but with another $x$ axis scale.

is repeated from Fig. 6. For the dark green curve, the GPS and the meteo stations in Payerne are excluded from the reconstruction. Mostly affected are the refractivities in the lowermost $2 \mathrm{~km}$ with an increase in RMS difference of 1-2 ppm, such that relative RMS differences have become $8-130 \%$. Since the AGNES and the SwissMetNet network are both not very dense in the region of Payerne, it is expected that the accuracy of wet refractivity reconstruction for all of Switzerland is quite well represented with the dark green curve in Fig. 9.

Now that the achievable accuracy in terms of absolute wet refractivities has been demonstrated, we continue the statistical analysis with relative differences between model and rs. The statistics of $3 \mathrm{yr}$ of data for the lower troposphere are shown in Fig. 10a-c, where we compare the collocation results for different input data. Figure 10a includes only ZWDs in the collocation and demonstrates the quality of reconstruction if we use GPS data. The median shows a distinct negative offset of $-16 \%$ at $\approx 1.5 \mathrm{~km}$ height and quartiles of $10 \%$ in the boundary layer. The negative offset has almost disappeared in Fig. 10b. Here, the collocation also includes $N_{\text {wet }}$ from ground meteo stations and shows a clear improvement of the quartiles to $5-7.5 \%$ relative difference below $1.5 \mathrm{~km}$. Furthermore, the strong asymmetry of the quartiles at heights between $3 \mathrm{~km}$ and $4 \mathrm{~km}$ of Fig. 10a has been greatly reduced

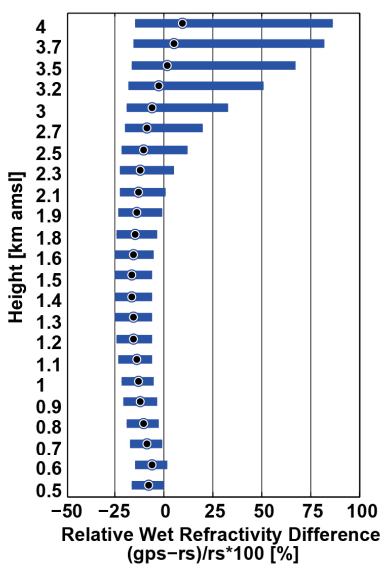

(a) $Z W D$

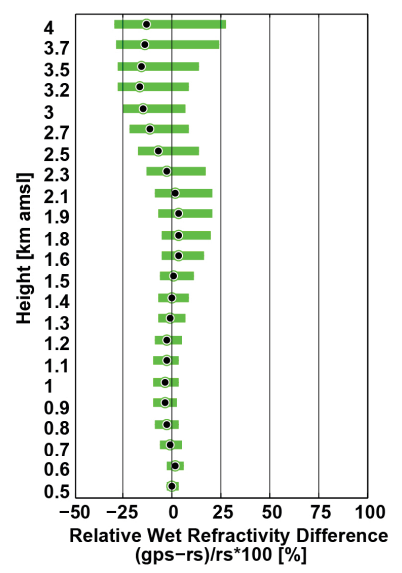

(b) $Z W D N_{w e t}$

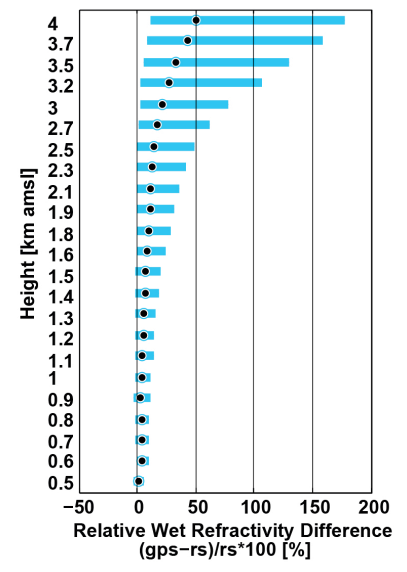

(c) $N_{\text {wet }}$

Fig. 10. (a) Box plot of the relative differences between COMEDIEderived wet refractivities with data from GPS only and the radiosonde. Boxes denote the 25 th and 75 th percentile and the median is marked inside the boxes. Total number of evaluated cases is 2132. (b) As for (a) but with COMEDIE-derived wet refractivities using data from GPS and ground meteorological stations. (c) As for (a) but using COMEDIE derived wet refractivities from data of ground meteorological stations only. Note that the abscissa is scaled differently to (a) and (b).

in Fig. 10b. In order to quantify the effect of the $N_{\text {wet }}$ data set on its own, it was separately included in the collocation (Fig. 10c). A linear trend of the median is observed that drifts away from the zero line. The spread has also increased with respect to Fig. 10b. Hence, a clear benefit comes from the combination of the two data sets.

Radio occultations deliver an atmospheric product that can be used to calculate point measurements of wet refractivity. They can be included in the collocation approach much the same way as ground meteo measurements of wet refractivity. There are 189 radio occultations available in the investigation area during the $3 \mathrm{yr}$ (Table 1). Therefore, only a limited number of COMEDIE calculation batches would actually contain one or more occultations in their data set. 


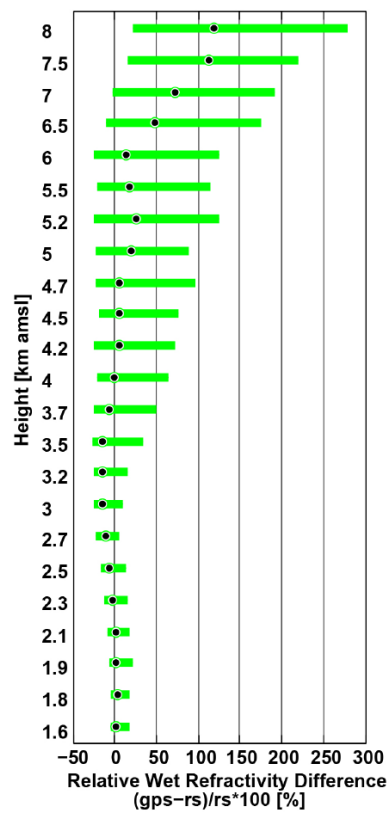

(a)

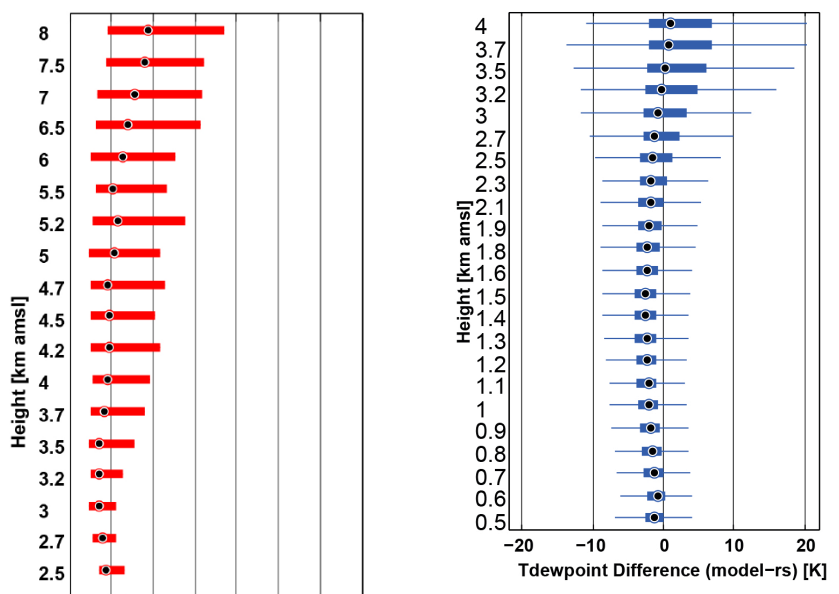

(a)

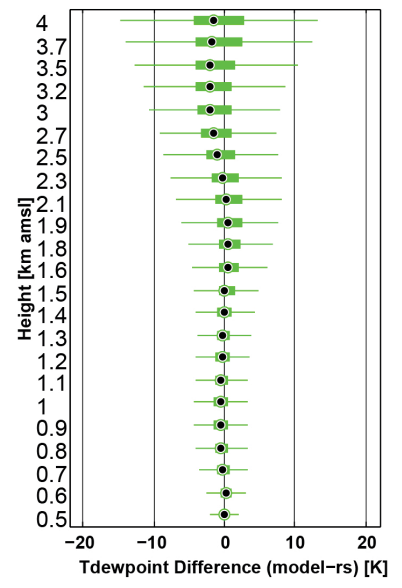

(b)

Fig. 13. (a) Box plot showing the differences between dew point temperature derived from COMEDIE wet refractivities and radiometer temperatures and dew point temperature entirely calculated with radiosonde data. COMEDIE wet refractivities were calculated using GPS zenith path delays only. Boxes denote the 25th and 75 th percentile. The median is marked inside the boxes. Lines show large offsets and extend from $q_{25 \%}-1.5 \cdot\left(q_{75 \%}-q_{25 \%}\right)$ to $q_{75 \%}+1.5 \cdot\left(q_{75} \%-q_{25} \%\right)$. They cover roughly $99 \%$ of the data spread if normal distribution is assumed. Further data is classified as outliers and not shown. (b) As for (a), but with wet refractivities from ground meteo stations as additional input data set in COMEDIE.

\subsection{Humidity profiles}

With the additional temperature profiles from the microwave radiometer, the wet refractivity profiles have been converted to dew point temperature. To display dew point temperature on a single profile basis, emagrams of the previously shown October cases for the GPS plus ground meteo solution have been determined in Fig. 12a and b. Beside the model quality of dew point temperature, also the quality of the radiometer temperatures can be demonstrated with the emagram. The smooth nature of the model solution is also noted here. In addition, the incapability to reconstruct the cloud layer between $3-4 \mathrm{~km}$ is shown in Fig. 12b. This is due to a lack of stations at that height in the vicinity of Payerne (Fig. 3).

The same statistical model to rs comparison as in Sect. 4.1 has been carried out on the basis of absolute differences of dew point temperature (Fig. 13a and b). Similarly to the relative wet refractivity differences in Fig. 10a and b, the differences in dew point temperature increase almost uniformly with height. This is due to the increased sensitivity of errors in wet refractivity on dew point temperature with decreasing temperature and hence, with height. In Table 4 it is shown that the influence of temperature error on dew point temperature is almost one order of magnitude lower than is the influence of wet refractivity, which means that the microwave 
Table 4. Formal sensitivity effects of errors in wet refractivity and temperature on dew point temperature and relative humidity. Valid for atmospheric values of $N_{\text {wet }}=10-50 \mathrm{ppm}$ and $T=273-293 \mathrm{~K}$, corresponding to values typical for the lower troposphere.

\begin{tabular}{lll}
\hline & $\begin{array}{l}1 \mathrm{ppm} \text { error } \\
\text { in } N_{\text {wet }}\end{array}$ & $\begin{array}{l}1 \mathrm{~K} \text { error } \\
\text { in temperature }\end{array}$ \\
\hline $\begin{array}{l}\text { Dew point temperature } \\
\text { Relative humidity }\end{array}$ & $0.2-1.1 \mathrm{~K}$ & $\leq 0.1 \mathrm{~K}$ \\
$1-3 \%$ & $1-12 \%$ \\
\hline
\end{tabular}

radiometer adds very little to the error figure of the model solution.

We also calculate profiles of relative humidity (Eq. 20) from microwave radiometer temperature and model refractivity of the combined solution of GPS and ground meteo. Figure 14 shows the statistics with respect to the radiosonde as mean and standard deviation of the difference. Systematic deviations from zero of maximum $7.3 \%$ and standard deviations of $12-20.0 \%$ are observed for the lower troposphere. Note that, contrary to error sensitivity in dew point temperature, where wet refractivity had much more influence than temperature, relative humidity is similarly affected by temperature and refractivity (Table 4).

\section{Discussion}

This study uses an interpolation technique to determine wet refractivity profiles from mainly GPS zenith path delays. Many other investigators have used the tomographic approach using slant path delays from the GPS processing to reconstruct wet refractivity fields. The slant paths, if fully recovered during the processing, do not have the averaging nature of zenith path delays and should hence contain information about the heterogeneity of wet refractivity in the atmosphere. The tomographic approach has been statistically validated in Perler (2011) for a one year period in Payerne, Switzerland. He obtains standard deviations of $\approx 10 \mathrm{ppm}$ at the ground, which decrease to $\approx 5 \mathrm{ppm}$ at $4500 \mathrm{~m}$ a.m.s.l. with respect to the radiosonde reference. With another tomographic method and for a dense network in southern France, Nilsson et al. (2007) arrive at $4-5 \mathrm{ppm}$ absolute error to a radiosonde reference and a relative error of $10 \%$ most of the time for the refractivity in the lower $2 \mathrm{~km}$ of the troposphere. The problem of the tomographic approach lies in the fact that path delays from ground based GPS stations have very limited capability to recover vertical structures in the atmosphere above the top station as has been shown by Champollion et al. (2005) or Perler et al. (2011). GPS tomography software with data from ground-based stations, therefore, rely on information other than actual measurements to retrieve meaningful fields. These are often constraints on the mutual dependence between refractivities. In the presented study here, such constraints were also integrated using

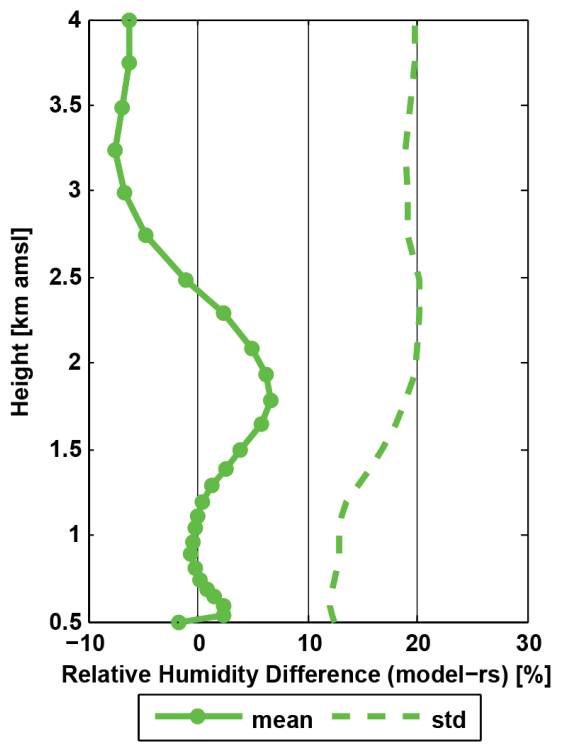

Fig. 14. Mean and standard deviation of the difference between relative humidity from the combined COMEDIE solution (GPS and ground meteo) and the radiosonde from the comparison with 2132 radiosonde cases.

a statistical parameter of assumed covariance matrix. Additionally, a trend function has been included that describes the structure of the general ZWD field. GPS tomography was not employed with the given network due to the sparsity of crossing rays that are especially important for the quality of tomographic reconstructions (Bender et al., 2009). Our ZWD only solution yields RMS differences (not shown) of 7-8 ppm (20-80\% relative RMS difference) below $2 \mathrm{~km}$ and $4 \mathrm{ppm}(130 \%)$ at $4 \mathrm{~km}$ height. The fact that the results with only zenith path delays are close in accuracy to other works that use slant path delays in a tomographic approach, confirms the known difficulties to profile atmospheric wet refractivity with delays from ground GPS stations. Additionally, it also demonstrates the strong influence of the constraints on the results. We do for example have a very similar station network at hand as Perler (2011) and our profiles are on average closer to those of the radiosonde than in his case, which is due to our constraints of an exponential deterministic function and strong correlations of the stochastic signal.

The least-squares collocation is capable of including other measurement types. In a first experiment, ground meteo stations have been included. Ground meteo station data has been previously included into GPS tomography and its beneficial effect has been shown (Manning et al., 2013) or has been suggested (Bosy et al., 2010). We show that including ground meteo measurements of wet refractivity has a very positive effect on the mean offset with respect to the radiosonde reference, particularly in the region $\leq 2 \mathrm{~km}$. Including $N_{\text {wet }}$ profiles from radio occultations has been shown to improve the accuracy in the upper troposphere. Due to 
the few occultations taking place in the study region during the $3 \mathrm{yr}$, radio occultations give little support to the overall $3 \mathrm{yr}$ solution. We still demonstrate that their continuation to the ground with GPS path delays and ground meteo measurements is feasible. Foelsche and Kirchengast (2001) demonstrate that a thorough ray-tracing approach together with slant paths from ground stations allows retrieval of the complete information contained in radio occultation delays.

The Raman Lidar is a measurement technique with a vertical resolution superior to our technique. For an operational Raman Lidar at Payerne, Switzerland, Brocard et al. (2013) demonstrate a relative humidity agreement of $2 \%$ for daytime and $5 \%$ for nighttime comparisons with radiosondes. Conversion from mixing ratio to relative humidity were carried out with temperatures from radiosondes. Standard deviations of this comparison are around 5\% (night) and 7\% (day) for most of the lower troposphere. At night, when humidity gradients at $1.5 \mathrm{~km}$ aboveground are often pronounced, standard deviation of the lidar minus sonde comparison reaches up to $10 \%$ at that height. This suggests that lidar profiles are also somewhat smoothed and do not fully catch strong gradients close to the boundary layer top, but far better than our profiles. Our relative humidity agreement is around $5 \%$, with standard deviations of $12-20 \%$. For the conversion of $N_{\text {wet }}$ to relative humidity, we use temperature from the microwave profiler, which adds further uncertainty to our retrieval, but is generally available, including times of fog and light rain, and not restricted to heights below cloud base. Exceptions occur in case of strong rain, where quality of temperature profiles from radiometer have not been sufficiently investigated yet. The easy maintenance, good data reliability and low costs due to shared use with other applications are the strengths of our solution, which is not a measurement technique as such, but an aggregation of data from a relatively large area ( $100 \mathrm{~km}$ radius). In contrast to the lidar that is very precise at one location, the aggregation aims at a certain representativeness. Due to costs, a dense radiosonde or lidar network would be difficult to setup and maintain. With respect to radiosondes, the temporal resolution of our data is more suited to follow the evolution of atmospheric humidity on timescales of hours. The smoothed profiles however, do not allow for an imaging of strong vertical humidity gradients correctly. The relative humidity uncertainty of the radiosonde is given as $5-10 \%$ (Table 2 ) with approximately $10 \mathrm{~m}$ average vertical resolution. This makes it a suitable reference in case of sharp humidity gradients.

Relative humidity is still one of the most difficult variables to forecast by a numerical weather prediction model. Forecast uncertainties in relative humidity of $10-20 \%$ are common (e.g. Wilhelm, 2012) and are thus of the same order of magnitude as our results. Since GPS, microwave radiometer and ground meteo stations together provide humidity information in near-realtime, we envisage a benefit of our profiles for applications of cloud and rain nowcasting. The profiles achieve dew point temperature quartiles $\leq 2 \mathrm{~K}$ below $2 \mathrm{~km}$ height and increase to $4.5 \mathrm{~K}$ at $4 \mathrm{~km}$. A possible product could be the calculation of CAPE (convective available potential energy) for thunderstorm detection or other indices related to the occurrence of precipitation events and their severity, before they can be detected and quantified by other means (e.g. weather radar).

\section{Conclusions}

We present results from an interpolation approach of GPS zenith wet delays and several data sets of point measurements of wet refractivity to reconstruct wet refractivity profiles. Water vapour profiles have been calculated, where temperature profiles from a microwave radiometer are available. Wet refractivity profiles from our processing are shown to have comparable accuracy to results from investigations that reconstruct refractivity with GPS tomography. Additional data sets, such as ground meteorological values or radio occultations improved the results. With respect to dew point temperature, a maximum median offset of $2 \mathrm{~K}$ and maximum quartiles of $4.5 \mathrm{~K}$ were achieved for the lower troposphere, combining the presently available data from a GPS and a ground meteo network in the western part of Switzerland. Collocation can incorporate a suite of data into a common least-squares framework. Possible further data sets to include would be Lidar profiles, refractivity gradients derived from rain radar clutter maps, differential delays from InSAR interferograms (with topographic phase removed), or zenith path gradients, the latter being a result of the GPS processing. The inclusion of zenith path delay gradients into collocations will be the next step. They contain information about azimuthal asymmetry in the tropospheric wet delay and are relatively easy to integrate into COMEDIE. The combination of many data sets already available in near-realtime of either integral or point measures of refractivity with collocation could be a valuable contribution to the nowcasting community or could provide a methodology to investigate individual instrument accuracies, the investigation profiting from mutually complemental instrumental strengths.

Acknowledgements. The authors would like to thank Elmar Brockmann from swisstopo for his invaluable support, processing and for providing us the GNSS data set. We also thank the MeteoSwiss staff for their support of this work, especially Dominique Ruffieux, Bertrand Calpini and their teams, for their leadership in making advanced remote sensing techniques operational for meteorologists and modelers. For proofreading and fruitful discussions, thanks go to Alain Geiger and Markus Rothacher from the Institute of Geodesy and Photogrammetry (ETH Zurich).

Edited by: A. Richter 


\section{References}

Bastin, S., Champollion, C., Bock, O., Drobinski, P., and Masson, F.: Diurnal cycle of water vapor as documented by a dense GPS network in a coastal area during ESCOMPTE IOP2, B. Am. Meteorol. Soc., 46, 167-182, 2007.

Bender, M., Dick, G., Wickert, J., Ramatschi, M., Ge, M., Gendt, G., Rothacher, M., Raabe, A., and Tetzlaff, G.: Estimates of the information provided by GPS slant data observed in Germany regarding tomographic applications, J. Geophys. Res.Atmos., 114, D06303, doi:10.1029/2008JD011008, 2009.

Bender, M., Dick, G., Ge, M., Deng, Z., Wickert, J., Kahle, H.G., Raabe, A., and Tetzlaff, G.: Development of a GNSS water vapour tomography system using algebraic reconstruction techniques, Adv. Space Res., 47, 1704-1720, 2011 a.

Bender, M., Stosius, R., Zus, F., Dick, G., Wickert, J., and Raabe, A.: GNSS water vapour tomography - expected improvements by combining GPS, GLONASS and Galileo observations, Adv. Space Res., 47, 886-897, doi:10.1016/j.asr.2010.09.011, 2011b.

Bolton, D.: The computation of equivalent potential temperature, Mon. Weather Rev., 108, 1046-1053, 1980.

Bosy, J., Rohm, W., Borkowski, A., Kroszczynski, K., and Figurski, M.: Integration and verification of meteorological observations and NWP model data for the local GNSS tomography, Atmos. Res., 96, 522-530, doi:10.1016/j.atmosres.2009.12.012, 2010.

Bosy, J., Kaplon, J., Rohm, W., Sierny, J., and Hadas, T.: Near realtime estimation of water vapour in the troposphere using ground GNSS and the meteorological data, Ann. Geophys., 30, 13791391, doi:10.5194/angeo-30-1379-2012, 2012.

Brocard, E., Philipona, R., Haefele, A., Romanens, G., Mueller, A., Ruffieux, D., Simeonov, V., and Calpini, B.: Raman Lidar for Meteorological Observations, RALMO - Part 2: Validation of water vapor measurements, Atmos. Meas. Tech., 6, 1347-1358, doi:10.5194/amt-6-1347-2013, 2013.

Champollion, C., Masson, F., Bouin, M.-N., Walpersdorf, A., Doerflinger, E., Bock, O., and van Baelen, J.: GPS water vapour tomography: preliminary results from the ESCOMPTE field experiment, Atmos. Res., 74, 253-274, doi:10.1016/j.atmosres.2004.04.003, 2005.

CIMO Guide: WMO Guide to Meteorological Instruments and Methods of Observation, Tech. Rep. WMO-No. 8, 7th Edn., World Meteorological Organization, Geneva, Switzerland, 2008.

Dach, R., Hugentobler, U., Fridez, P., and Meindl, M.: Bernese GPS Software Version 5.0, Astronomical Institute, University of Bern, 2007.

Eckert, V., Cocard, M., and Geiger, A.: COMEDIE (Collocation of Meteorological Data for Interpretation and Estimation of Tropospheric Pathdelays), Teil I: Konzepte, Teil II: Resultate, Tech. Rep. 194, grauer Bericht, ETH Zürich, 1992a.

Eckert, V., Cocard, M., and Geiger, A.: COMEDIE (Collocation of Meteorological Data for Interpretation and Estimation of Tropospheric Pathdelays), Teil III: Software, Tech. Rep. 195, Grauer Bericht, ETH Zürich, 1992b.

Essen, L. and Froome, K. D.: The refractive indices and dielectric constants of air and its principal constituents at $24,000 \mathrm{Mc} / \mathrm{s}$, P. Phys. Soc. Lond. B, 64, 862-875, 1951.
Foelsche, U. and Kirchengast, G.: Tropospheric water vapor imaging by combination of ground-based and spaceborne GNSS sounding data, J. Geophys. Res.-Atmos., 106, 27221-27231, doi:10.1029/2001JD900230, 2001.

Foelsche, U., Syndergaard, S., Fritzer, J., and Kirchengast, G.: Errors in GNSS radio occultation data: relevance of the measurement geometry and obliquity of profiles, Atmos. Meas. Tech., 4, 189-199, doi:10.5194/amt-4-189-2011, 2011.

Hirter, H.: Mehrdimensionale Interpolation von Meteorologischen Feldern zur Berechnung der Brechungsbedingungen in der Geodäsie, Mitteilung 64, Inst. of Geodesy and Photogrammetry, ETH Zurich, 1998.

Ho, S.-P., Kirchengast, G., Leroy, S., Wickert, J., Mannucci, A. J., Steiner, A., Hunt, D., Schreiner, W., Sokolovskiy, S., Ao, C., Borsche, M., von Engeln, A., Foelsche, U., Heise, S., Iijima, B., Kuo, Y.-H., Kursinski, R., Pirscher, B., Ringer, M., Rocken, C., and Schmidt, T.: Estimating the uncertainty of using GPS radio occultation data for climate monitoring: intercomparison of CHAMP refractivity climate records from 2002 to 2006 from different data centers, J. Geophys. Res.-Atmos., 114, D23107, doi:10.1029/2009JD011969, 2009.

Jacobson, M. Z.: Fundamentals of Atmospheric Modeling, 2nd Edn., Cambridge Uni. Press, 2005.

Kuo, Y.-H., Wee, T.-K., Sokolovskiy, S., Rocken, C., Schreiner, W., Hunt, D., and Anthes, R.: Inversion and error estimation of GPS radio occultation data, J. Meteorol. Soc. Jpn. Ser. II, 82, 507-531, 2004.

Löhnert, U. and Maier, O.: Operational profiling of temperature using ground-based microwave radiometry at Payerne: prospects and challenges, Atmos. Meas. Tech., 5, 1121-1134, doi:10.5194/amt-5-1121-2012, 2012.

Lutz, S.: High-Resolution GPS Tomography in View of Hydrological Hazard Assessment, Vol. 76 of Geodätisch-geophysikalische Arbeiten in der Schweiz, Swiss Geodetic Commission, 2009.

Manning, T., Zhang, K., Rohm, W., Choy, S., and Hurter, F.: Detecting severe weather using GPS tomography: an Australian case study, Journal of Global Positioning Systems, 11, 58-70, 2012.

Manning, T., Rohm, W., Zhang, K., Hurter, F., and Wang, C.: Determining the 4-D dynamics of wet refractivity using GPS tomography in the Australian region, in: Earth on the Edge: Science for a Sustainable Planet, edited by: Rizos, C. and Willis, P.: Proceedings of the IAG General Assembly, Melbourne, Australia, 28 June-2 July, 2011, IAG Symp., 139, ISBN 978-3-642-372216, 2013.

Moritz, H.: Least-squares collocation, Rev. Geophys., 16, 421-430, 1978.

Nash, J., Oakley, T., Vömel, H., and Wei, L.: WMO Intercomparison of High Quality Radiosonde Systems Yanjiang, China, 12 July-3 August 2010, Tech. Rep. WMO/TD-No. 1580, World Meteorological Organization, Geneva, Switzerland, 2011.

Niell, A. E.: Global mapping functions for the atmosphere delay at radio wavelengths, J. Geophys. Res, 101(B2), 3227-3246, doi:10.1029/95JB03048, 1996.

Nilsson, T. and Gradinarsky, L.: Water vapor tomography using GPS phase observations: simulation results, IEEE T. Geosci. Remote, 44, 2927-2941, doi:10.1109/TGRS.2006.877755, 2006. 
Nilsson, T., Gradinarsky, L., and Elgered, G.: Water vapour tomography using GPS phase observations: results from the ESCOMPTE experiment, Tellus A, 59, 674-682, doi:10.3402/tellusa.v59i5.15150, 2007.

Perler, D.: Water Vapor Tomography using Global Navigation Satellite Systems, diss., Nr. 20012, ETH Zürich, doi:10.3929/ethza-006875504, Eidgenössische Technische Hochschule ETH Zürich, 2011.

Perler, D., Geiger, A., and Hurter, F.: 4-D GPS water vapor tomography: new parameterized approaches, J. Geodesy, 85, 539-550, 2011.

Rohm, W.: The ground GNSS tomography - unconstrained approach, Adv. Space Res., 51, 501-513, doi:10.1016/j.asr.2012.09.021, 2013.

Rohm, W. and Bosy, J.: The verification of GNSS tropospheric tomography model in a mountainous area, Adv. Space Res., 47, 1721-1730, doi:10.1016/j.asr.2010.04.017, 2011.
Rüeger, J. M.: Refractive Index Formulae for Radio Waves, in: Proceedings, FIG Technical Program, XXII FIG International Congress, Washington DC, JS28, 12 pages, 19-26 April, 2002.

Scherllin-Pirscher, B., Steiner, A. K., Kirchengast, G., Kuo, Y.-H., and Foelsche, U.: Empirical analysis and modeling of errors of atmospheric profiles from GPS radio occultation, Atmos. Meas. Tech., 4, 1875-1890, doi:10.5194/amt-4-1875-2011, 2011.

Troller, M.: GPS based Determination of the Integrated and Spatially Distributed Water Vapor in the Troposphere, Vol. 67 of Geodätisch-geophysikalische Arbeiten in der Schweiz, Swiss Geodetic Commission, 2004.

VARS Documentation: Variational Atmospheric Retrieval Scheme (VARS) for GPS Radio Occultation Data, COSMIC Project Office, University Corporation for Atmos. Res., version 1.1, available at: http://cdaac-www.cosmic.ucar.edu/cdaac/doc/ documents/1dvar.pdf (last access: 27 May 2013), 2005.

Wilhelm, M: COSMO-2 Model Performance in Forecasting Foehn: a Systematic Process-Oriented Verification, Veröffentlichungen der MeteoSchweiz, 89, 64 pp., 2012. 